\title{
THE VALUE OF TESTOSTERONE PROPIONATE IN HYPERTHYROIDISM.
}

\author{
By S. LEVY SIMPSON, M.A., M.D., M.R.C.P.
}

(Physician, Willesden General Hospital; Consulting Physician, Soho Hospital for Women.)

The hormone therapy of hyperthyroidism has, hitherto, been unsatisfactory. Working on the hypothesis that stimulation by the pituitary thyrotropic hormone might be a factor, Spence endeavoured to suppress pituitary activity by large doses of cestrin, but the patients showed no appreciable improvement. Insulin may occasionally be of slight benefit in enabling the patient to regain some loss of weight. It sometimes happens that patients with hyperthyroidism may appear to improve during the first part of pregnancy, although the condition is usually aggravated in the latter part. Thinking that such improvement might be due to activity of corpus luteum, I tried treating hyperthyroidism with progesterone. No apparent improvement occurred, although this might be explained by the inadequate dosage.

It occurred to me that testosterone propionate might be of value in hyperthyroidism for the following reasons:-

(I) The disease is much more common in females, and testosterone suppresses ovulation (Zuckerman, Loeser), and possibly œstrin secretion.

(2) In female rats, testosterone may produce progestatrenal changes in the uterus, simulating pseudo-pregnancy (Korenchevsky and Hall, McKeown and Zuckerman).

(3) Experimentally, it diminishes the activity of the pituitary, and might, in this way, diminish the secretion of pituitary thyrotropic hormone.

(4) I had found that it appeared to have a marked anabolic effect in a thin male castrate; (subsequent to the thyroid experiments, I have observed an anabolic effect in a neurotic wasted female).

(5) Virile females excreting an excess of androgenic hormone (e.g. in the case of adrenal tumours) become fat.

\section{Results :-}

Case 1. K.C. Female. Aged 17:

The history was apparently of three months' duration, and the condition was an example of a severe case of exophthalmic goitre. There was marked exophthalmos; the thyroid was diffusely enlarged to a considerable extent; tremor and excitability were prominent features. She continued work until one month before admission, but then became too weak and tired. Menstruation commenced at age of $15 \frac{1}{2}$, and was scanty, but regular. Patient weighed 8 st. 7 lbs., and said that she had not lost weight appreciably.

Testosterone was commenced on October 1st, $20 \mathrm{mgs}$. three times weekly. The weight gradually increased, and on October 26th was 8 st. 13 lbs. The dose of testosterone was then increased to $30 \mathrm{mgs}$. three times weekly, and on November 12th 
the weight had increased to 9 st. 6 lbs. The patient looked and felt very much better. The thyroid gland was not very much smaller, and the pulse rate, which varied between 110 and 120, was not apparently affected. The patient then continued to come to the hospital twice a week for the injection of 50 mgs. testosterone. Her weight has remained about the same, with slight fluctuations both ways. The thyroid has become somewhat smaller, and the pulse rate varies between 100 and 110.

The patient is more than pleased with her feeling of general well-being, and is quite unwilling to consider operation. Nevertheless, in spite of the striking gain in weight of nearly a stone, one would not conclude that, up to the present, there has been a decisive influence on the other features of the disease.

Case 2. V.C. Female. Aged 40:

This appeared to be an example of a toxic adenoma of the thyroid, with a history of some months' duration. There was an irregular enlargement of the thyroid; exophthalmos was slight, and nervous symptoms were not prominent. The pulse rate varied between 100 and 120 .

From the 18 th to the $23 \mathrm{rd}$ November the patient received $15 \mathrm{mgs}$. of testosterone on three occasions. From the 23rd November to 1st December, $30 \mathrm{mgs}$. on three occasions; from the 1st December to 8th December, 50 mgs. daily; and from the 8th to the 18th December, 50 mgs. three times weekly. There was no appreciable change in the patient's weight, namely, 8 st. $6 \mathrm{lbs}$., nor was there any obvious objective improvement, although the patient was convinced that she felt very much better; and, although she originally came in for a thyroidectomy, now refused to be operated upon. There was, however, an interesting change for the better in the electrocardiograms. Thus, on the 23rd November, Dr. Peter Meyer reported:-

Regular sinus rhythm, rate $109 / \mathrm{min}$.

$\mathrm{P}$-waves normal, P-Q interval normal.

Small Q-waves in leads I and II. Notching of QRS in lead III.

Low voltage $T$-waves in leads I, II and III.

Lead IV (chest-left leg): T-wave is positive, or slightly diphasic. Well marked Q-wave.

Opinion: Changes seen in the $\mathrm{T}$-waves in all leads are suggestive of some myocardial damage. Otherwise no abnormality. Moderate tachycardia.

On the 20th December, his report was as follows:-

Slightly irregular sinus rhythm (respiratory arrhythmia), rate $91 / \mathrm{min}$.

P-waves normal, P-Q interval normal, QRS normal in all leads. Notching of QRS in lead III. Well marked positive T-waves in leads I and II, isoelectric in lead III.

Lead IV (chest-left leg) is normal.

Opinion: There are definite changes in the electrocardiogram when compared to the tracing taken in November. The rate is slower. The different shape of the $T$-waves in leads I, II and IV suggests a definite improvement in the heart muscle. The tracing should now be regarded as normal, apart from respiratory arrhythmia and moderate sinus tachycardia.

Case 3. E.L. Female. Aged 24:

This was a relatively mild case of exophthalmic goitre. In July, 1937, she complained of nervousness, and loss of weight, and was diagnosed as having thyroid trouble. 
She believed that the onset of the present disorder was in October, 1936, following influenza.

On examination patient appeared thin $(7$ st. $10 \mathrm{lbs}$.), restless and excitable, with slight exophthalmos, fine tremor of the hands, and slight diffuse enlargement of the thyroid.

On the 3rd March testosterone propionate therapy was commenced, 50 mgs. intramuscularly, on alternate days. On the 16th March the weight had increased by $1 \frac{1}{4} \mathrm{lbs}$. to 8 stone, and the injections were then increased to $50 \mathrm{mgs}$. daily. The weight then began to increase more rapidly, and was 8 st. $7 \mathrm{lbs}$. on the 28th March, and $8 \mathrm{st}$. $9 \mathrm{lbs}$. on the 31st March, when she was discharged. The swelling of the thyroid had diminished, and was hardly palpable. The pulse rate, which had been between 80 and 100 , now tended to remain between 80 and 90 . Therapy is being continued as an out-patient. The patient felt, and looked, very much better.

\section{Summary of Results :-}

The most striking feature in the two cases of exophthalmic goitre was the rapid increase in weight, approximately one stone in three weeks. This is all the more remarkable, when one remembers the difficulty of making an active hyperthyroid patient increase in weight. The therapy was not commenced until the patients had been in hospital for some ten days, and until a fairly stable weight level had been obtained. No therapy other than small doses of luminal sodium was given, and that from the first day of admission.

In the less severe case (No. 3) there was a favourable influence on the size of the gland, and on the pulse rate, but this was not very appreciable in the more severe case (No. I). It may be that, started early, or continued for a long period, testosterone propionate might prove to have a fundamental influence on the course of exophthalmic goitre; it is possible however that the " anabolic" effect may be non-specific and partly due to water retention.

In the case of toxic adenoma (No. 2), there was no appreciable gain in weight, but it is interesting to record the apparent favourable influence on the heart, as judged by the electrocardiograms. Unfortunately, electrocardiograms were not taken in the other two cases. Korenchevsky and others have drawn attention to the diminution in the size of the heart following castration, and the hypertrophy that follows with testosterone substitution therapy.

In Case I there has been complete amenorrhœa during the continuation of testosterone propionate therapy (six months), although menstruation was regular previous to this. In Case 3 a normal menstrual period occurred on the 8th March, although testosterone therapy was commenced on the 3 rd March. There has been no time for subsequent observations.

In all cases, but particularly in the two examples of exophthalmic goitre, there has been a very definite favourable influence on the patients' general well-being, and this influence has been obvious to all observers, medical and lay. I have not yet observed any adverse effects of the therapy, and there has been no indication of resulting hirsutism, or of enlargement of the clitoris; nor have the breasts been appreciably influenced.

I wish to thank the firms of Ciba and Organon for kindly supplying synthetic testosterone propionate in concentrated form. 